\title{
Potencialidades da aula de campo no estudo de Geografia na região da Foz do Rio Jucu no bairro Barra do Jucu/Vila Velha/ES
}

The potentials of field classes in the study of Geography in Jucu River's mouth, Barra do Jucu/Vila Velha/ES

Rômulo Marconi Carneiro Karolayne Pinheiro dos Santos

Tainá Guimarães Ricardo

Resumo: $O$ presente artigo $^{1}$ se propôs a apresentar uma prática de ensino da Geografia no âmbito do Programa Residência Pedagógica em Geografia, da Universidade Federal do Espírito Santo (UFES), com estudantes do $6^{\circ}$ ano de uma escola-campo, localizada no município de Vila Velha/ES. A atividade descrita neste artigo fundamenta-se na reflexão da práxis preconizada por Freire (2001) e tem como objetivo relacionar os limites e possibilidades da aula de campo e suas contribuições para o desenvolvimento crítico e dialógico do ensino da Geografia com o ambiente no qual os estudantes estão inseridos. Baseia-se na dificuldade de compreensão e entendimento de forma integrada do ensino teórico da Geografia com o dia a dia dos(as) estudantes. A metodologia adotada apoia-se na Pesquisa com o cotidiano de Ferraço (2007) e Alves (2001). O percurso metodológico ocorreu em três etapas: o pré-campo, o campo e o pós-campo, que resultou na produção de histórias em quadrinhos sobre a temática estudada. Constatou-se a importância da aula de campo para a compreensão fora da escola, o que é estudado dentro dela e que a adoção deste tipo de metodologia potencializa o ensino da Geografia e motiva os estudantes a uma postura crítico-reflexiva, ao dinamizar o processo de ensino-aprendizagem.

Palavras-chave: Aula de campo. Ensino de Geografia. Aprendizagem. Cotidianos escolares. Barra do Jucu.

Abstract: This paper aims to present a Geography teaching practice within the scope of the University of Espírito Santo (UFES)'s Residência Pedagógica Program, with 6th grade students from a field school located in Vila Velha/ES. The activity described in this paper is based on the thoughts of Freire's (2001) praxis and aims to explore the limits and possibilities of field trips and its contributions to critical and dialogical development of Geography teaching connected to the environment in which students are inserted. It is based on the comprehension difficulties and the theoretical understanding of Geography in an integrated way with the students' daily lives. The methodology adopted is based on researches of the everyday by Ferraço (2007) and Alves (2001). The methodological path took place in three stages: the pre-field, the field and the post-field, which resulted in the production of comic books on the subject studied. The importance of field classes was verified in the comprehension of the out of school environment and the subjects studied inside of school. The use of these methodologies potentiates the teaching of Geography and motivates the students to a critical-reflexive stance, by dynamizing the teaching-learning process.

\footnotetext{
${ }^{1}$ Fruto da pesquisa do Trabalho de Conclusão de Curso de mesmo título.
} 
Keywords: Field classes. Geography teaching. Learning. School quotidian. Barra do Jucu.

\section{Quero sair desse quarto, quero olhar pela minha janela (Tempo, 2010) ${ }^{2}$}

A Geografia escolar, ainda apresentada nos moldes do ensino tradicional, que expõe de forma desvinculada os conteúdos, pouco contribui para a formação cidadã a qual é remetida na Lei de Diretrizes e Bases da Educação Nacional (BRASIL, 1996). O ensino convencional na Geografia é exposto como a descrição, enumeração e memorização de elementos e conceitos, de forma fragmentada e desconexa com a realidade dos espaços/lugares e cotidianos. Esse modo de ensino pouco valoriza a participação direta dos(as) estudantes no processo de ensino-aprendizagem, contradizendo o que preconiza a Base Nacional Comum Curricular (BRASIL, 2017), para a qual os(as) estudantes devem ser protagonistas de seus aprendizados. Para a superação desse método de ensino, é fundamental a adoção de práticas pedagógicas que reconheçam e ressaltem o desenvolvimento dos aspectos cognitivos dos (as) estudantes, que façam valer a autonomia, autoria, inventividade, criticidade, pluralidade de estéticas em seus discursos.

Os impasses da formação inicial de professores(as) são também abordados neste trabalho. A dificuldade de associação entre teoria e prática na educação é fruto do distanciamento entre instituições de ensino superior, e suas licenciaturas, e as unidades básicas de ensino. Para a suplantação desse entrave, é imprescindível a criação e efetivação de políticas e práticas educacionais. Desta maneira, o Programa Residência Pedagógica, financiado pela Coordenação de Aperfeiçoamento de Pessoal de Nível Superior (CAPES), é uma das ações que integram a Política Nacional de Formação de Professores, que objetiva o aperfeiçoamento, a reformulação, a consolidação e a adequação de práticas, metodologias, currículos e habilidades entre as instituições de ensino superior e as escolas. Este artigo sintetiza uma pesquisa

\footnotetext{
2 Nos títulos iniciais de cada tópico são apresentados trechos de letras das músicas da banda Casaca, originária do bairro Barra do Jucu, formada o início do ano 2000, a fim de valorizar a cultura local, além de dar aspectos didáticos para a pesquisa.
} 
realizada por um grupo de licenciandos do Curso de Licenciatura em Geografia da Universidade Federal do Espírito Santo (UFES) desenvolvida no ano de 2019 a partir das muitas vivências proporcionadas durante o Programa Residência Pedagógica, em uma Unidade Municipal de Ensino Fundamental pertencente à rede pública de ensino localizada no município de Vila Velha/ES. Isso resultou em um trabalho de conclusão de curso (HENRIQUE JÚNIOR et al., 2019), atendendo, assim, aos objetivos propostos pelo programa, que consiste na coleta de dados e diagnósticos sobre o processo de ensinoaprendizagem com participação ativa dos envolvidos e a inclusão de metodologias e práticas que estimulem mudanças positivas para os currículos e práticas discentes e docentes.

Os vastos trabalhos de Paulo Freire vêm contribuindo para a reformulação e reflexão sobre o sistema educacional e sua importância para a criação e/ou fortalecimento do senso crítico dos(as) estudantes. Em seu livro Pedagogia da Autonomia, Paulo Freire (2001) discorre sobre a importância do ensino, que exige reflexões críticas sobre a prática docente. Ele afirma que "por isso é que, na formação permanente dos(as) professores(as), o momento fundamental é o da reflexão crítica sobre a prática. É pensando criticamente a prática de hoje ou de ontem que se pode melhorar a próxima prática" (FREIRE, 2001, p. 43).

Em consonância com o exposto, o esforço para a exposição de uma Geografia escolar com um caráter questionador, relacional, instigante e que proporcione e estimule o protagonismo estudantil, destacamos como a problemática deste trabalho as contrariedades e limitações de assimilação de forma integrada do ensino teórico da Geografia com a realidade dos(as) estudantes e dos lugares, que, de acordo com Paulo Freire, "o pensar abstrato dos alunos se torna em um pensar concreto" (FREIRE, 1987, p. 97) - isso se dá, também, por meio de fotografias, narrativas, conversas e produção de conteúdo em sala de aula.

Nesta perspectiva de investigação por metodologias que possam romper com essa desconexão entre teoria e prática, a aula de campo se torna um campo fértil e um instrumento fundamental para compreender e auxiliar a 
leitura do espaço, estreitando a relação entre a teoria e prática. "Não há ensino sem pesquisa e pesquisa sem ensino" (FREIRE, 2001, p. 32). Entendemos que a prática de realização de aula de campo tem importância no processo de ensino-aprendizagem, viabilizando aos estudantes a observação e as vivências, ao aproximar compreensões empíricas, de seus cotidianos e/ou adquiridas durante a aula de campo, com os saberes teóricos trabalhados em sala de aula. Vale reiterar que, segundo os Parâmetros Curriculares Nacionais (PCN), parte das ações educativas para o ensino fundamental inclui a leitura da paisagem realizada a partir da investigação do espaço local.

Os objetivos propostos consistem em relacionar os limites $\mathrm{e}$ as possibilidades da aula de campo e suas contribuições para o desenvolvimento do senso crítico e dialógico do ensino da Geografia com o ambiente que os estudantes estão inseridos. Para atingir tal objetivo, é imprescindível a associação dos conteúdos curriculares da Geografia, utilizando como mecanismo a aula de campo; estimular nos estudantes uma postura críticoreflexiva a partir da experimentação em campo do aprendizado e percepções fora do ambiente escolar; paralelamente, criar um momento e espaço para que possam utilizar-se de sua criatividade, autonomia e entendimento do processo, que resulta na confecção de histórias em quadrinhos (HQs).

Para isso, buscamos base teórica no que consiste nos estudos nos/dos cotidianos embasados por Ferraço (2007) e Alves (2001), partindo do princípio da escuta dos sujeitos das escolas para, a partir dessa escuta e com eles, observar possíveis caminhos para trabalhar, de tal forma alcançar os objetivos propostos da pesquisa.

\section{Apague toda essa besteira de memória, reconstrua tudo outra vez (Seu, 2007)}

A metodologia utilizada, que visa abordar os cotidianos vividos e construídos pelos (as) estudantes, apoia-se na escuta dos sujeitos das escolas, a fim de fortalecer processos contra-hegemônicos de políticas educacionais cotidianas (FERRAÇO, 2007) - esses processos são fundamentalmente criados pela ciência moderna dentro do currículo. 
Alves (2001) nos permite compreender a complexidade existente no espaço-tempo da escola, captar os saberes, os valores e as crenças que são tecidas no interior desta, além de nos possibilitar envolver e considerar todos os sujeitos escolares, (re)significando nossos/seus saberes-fazeres. Um dos movimentos citados por Alves (2001), fundamental para entender as lógicas do cotidiano, diz respeito a "narrar a vida e literaturizar a ciência". O conhecimento adquirido durante aula de campo pretende ser concretizado por meio da construção de narrativas criadas pelos (as) estudantes, as quais valorizam as dimensões de autoria, autonomia, legitimidade, beleza e pluralidade de estética dos discursos (FERRAÇO, 2007) dos sujeitos protagonistas nesse processo de ensino-aprendizagem.

A prática docente deve ser marcada pelo processo de análise e renovação de seus instrumentos e estratégias metodológicas, disposto a aprimorar o sistema de ensino vigente que tem apresentado fragilidades multifatoriais, como a ineficácia de algumas posturas didáticas tradicionais, como o uso único e exclusivo de livros didáticos e do quadro negro (ou branco). Logo, o processo de ensino requer mobilizações que promovam a aprendizagem, trazendo ao âmbito escolar não só as temáticas atuais, mas as formas alternativas de transposição didática, ademais a necessidade de aproximação dos conteúdos programáticos com o cotidiano e as experiências socioespaciais do(a) estudante - sendo indispensável que o(a) professor(a) seja consciente do seu papel de formador de opiniões e articulador de novas estratégias de ensino e aprendizagem, tornando o processo mais atraente e prazeroso para os(as) estudantes e docentes.

A partir disso, nos dedicamos na pesquisa de possíveis recursos didáticos e pedagógicos alternativos que se enquadram com a proposta e temática do projeto. Escolhemos os seguintes instrumentos: a aula de campo aliada à produção de histórias em quadrinhos. Posto isto, a aula de campo é um método que proporciona aos estudantes, maior contato com os elementos físicos estudados em sala de aula.

Todavia, neste presente trabalho optamos pela junção da aula de campo com atividades lúdicas e dinâmicas, que se constituem uma poderosa 
ferramenta, que possibilita trabalhar os conteúdos, em especial o geográfico, de modo a potencializar o senso crítico e criativo único de cada estudante.

O uso da linguagem não convencional no ensino da Geografia é uma articulação com as novas propostas de ensino, que busca apreensão da complexidade do mundo, mediada por diferentes representações, sendo capaz de escrevê-lo sob diversos aspectos e ópticas. Portanto, elegemos o artifício da produção de histórias em quadrinhos, reconhecido como ferramenta pedagógica no Brasil com a promulgação da Lei de Diretrizes e Bases da Educação Nacional (BRASIL, 1996), como sendo uma boa e eficiente estratégia para utilização com fins didáticos na sala de aula. Uma opção viável e agradável de reunir a leitura, escrita, criatividade, resultando em um maior envolvimento e interesse do (a) estudante pelo estudo de Geografia.

\section{Metodologia aplicada em sala de aula}

Para fins de viabilizar a pesquisa, trabalhamos com as três turmas de sexto ano da escola-campo contemplada pelo Programa Residência Pedagógica. A escolha da série/ano baseou-se nos conteúdos programáticos da Base Nacional Comum Curricular (BRASIL, 2017) e na grade curricular do município de Vila Velha, na qual constam conteúdos como hidrologia e geomorfologia - assuntos que tangem a proposta deste trabalho.

O projeto foi dividido em três partes:

1) O pré-campo - consistiu em 4 aulas expositivas direcionadas à temática, utilizando o livro didático, apresentação em PowerPoint, atividades lúdicas e avaliação. Os conteúdos trabalhados foram "Distribuição das águas continentais", "Rios e suas partes integrantes", "Águas subterrâneas", "O uso das águas continentais", "Escassez de água potável", "Importância da água", "Ciclo da água", "Distribuição das águas no planeta" e "Usos das águas oceânicas". Durante todas as apresentações dos conteúdos, havia a aproximação à realidade do bairro e do município, em especial à bacia hidrográfica do Rio Jucu.

2) O Campo - consistiu na ida ao bairro Barra do Jucu e ao Parque Natural Municipal de Jacarenema, ambos localizados no município de Vila 
Velha/ES. Nesta oportunidade, os (as) estudantes fizeram observações e registros fotográficos/croquis dos ambientes visitados e anotações das explicações feitas pela professora regente e residentes.

3) O pós-campo - consistiu na seleção de temáticas, de informações e registros fotográficos e ilustrações feitas pelas (os) estudantes; e na compilação para a produção, em grupos pré-definidos, de uma história em quadrinhos.

\section{Eu vou na frente pra quebrar essa corrente que segura essa gente, que não deixa ela vencer (Batuqueiro, 2002)}

Na fase pré-campo, apresentamos o projeto para as turmas e iniciamos uma sequência de quatro aulas de Geografia. Aulas essas com assuntos pertinentes ao que seria visto posteriormente na aula de campo, dando enfoque nas questões do ciclo da água, bacias hidrográficas e áreas afins que estão presentes no conteúdo programático do sexto ano. Para além, sempre buscando estabelecer conexões com o cotidiano do (a) estudante.

A aula de campo foi realizada com a presença das professoras titulares de Geografia e Ciências, reforçando o caráter interdisciplinar e relacional do projeto, e a participação e colaboração de 38 estudantes, além dos(as) integrantes do Programa Residência Pedagógica. Todos os (as) participantes da aula de campo foram orientados a terem um olhar geográfico e crítico sobre os aspectos naturais, econômicos e socioculturais que seriam vistos, além de realizarem registros fotográficos, ilustrações e anotações, caso necessário, de questões e/ou particularidades que Ihes chamassem a atenção.

A aula de campo foi estruturada e contou com 6 paradas dentro da região trabalhada. 
Figura 1 - Localização Pontos de parada da aula de campo

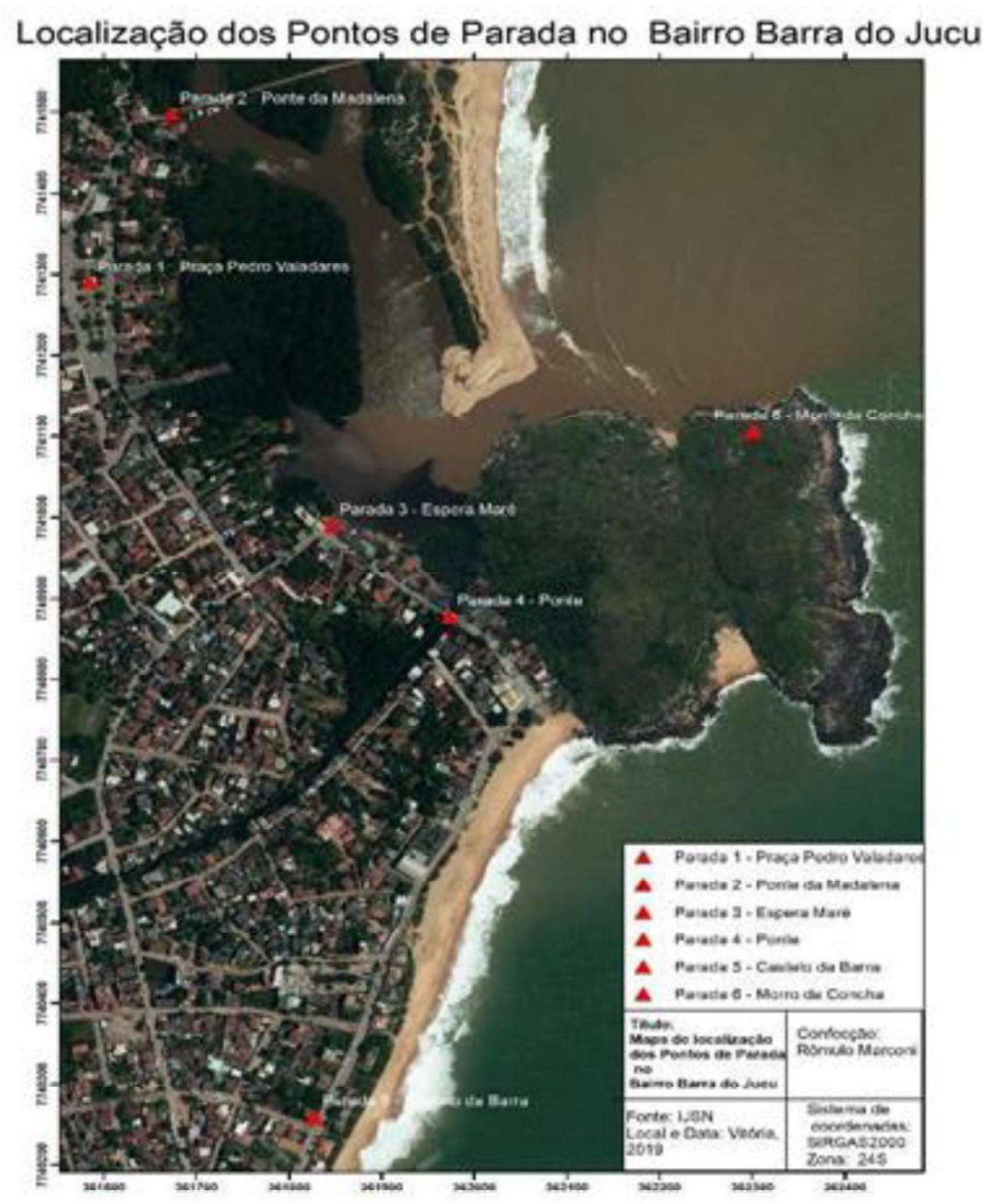

Fonte: Elaborado pelos autores utilizando o software Qgis 3.10.

$1^{\text {a }}$ parada - Praça Pedro Valadares. Nesse ponto, as professoras de Geografia e Ciências, com o auxílio dos (as) integrantes do Programa Residência Pedagógica, fizeram um breve histórico sobre o processo de ocupação do bairro: quem ali vivia e como viviam.

$2^{a}$ parada - Ponte da Madalena, construída em 1896, ligando o Parque Natural Municipal de Jacarenema ao bairro Barra do Jucu. A ponte leva esse nome em homenagem a uma antiga moradora local, que foi também homenageada na música "Madalena do Jucu", regravada pelo sambista Martinho da Vila. Desse ponto foi possível observar a presença do sistema manguezal e seus aspectos físicos, como o formato da vegetação com suas raízes expostas e o tipo de solo. Outro aspecto presenciado foi a retirada da 
mata ciliar, sendo um dos motivos do assoreamento ao longo do curso do rio, com a presença de diversos bancos de areia, além da turbidez da água notada e questionada pelos estudantes.

$3^{a}$ parada - Acesso à margem do Rio Jucu e ao manguezal, ao lado do restaurante Espera Maré, onde foi debatida a importância do sistema manguezal enquanto um berçário natural; a influência dos movimentos das marés no ecossistema, que foi observada através das evidências e marcações geológicas no Morro da Concha; a contaminação do manguezal com lançamento direto e indireto da rede de esgoto, além de estar sendo utilizado como depósito de lixo. Alguns estudantes indagaram acerca da qualidade da água e perguntaram: "é essa água que a gente bebe?" Com isso, explicamos que a captação de água é feita mais a montante no rio e que a água passa por tratamentos químicos até chegar às nossas residências.

$4^{a}$ parada - Ponte a caminho da Praia do Barrão. Esse ponto viabilizou a constatação recorrente do despejo irregular do esgoto em um corpo hídrico com ligações diretas com o Rio Jucu, além do processo de assoreamento, que tem como um dos fatores a ocupação irregular próxima às margens do rio.

Figura 2 - Parada sobre a ponte

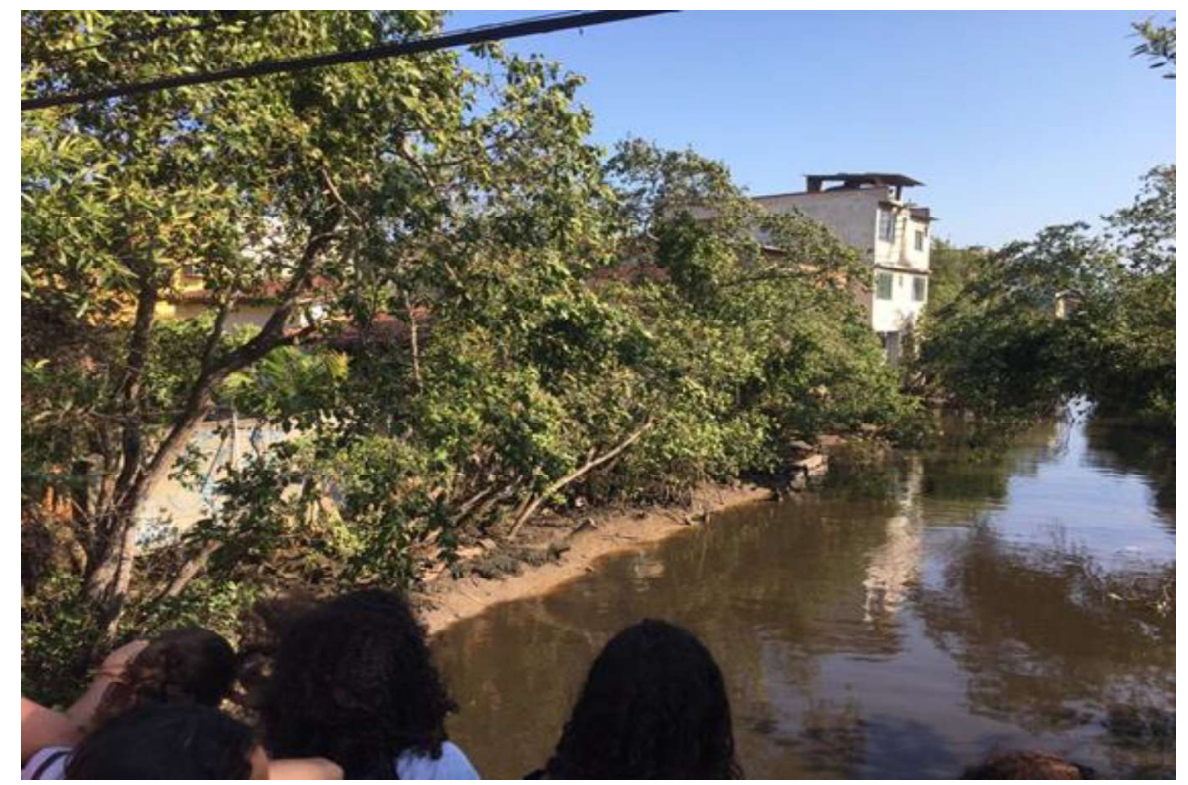

Fonte: Autoria própria (2019)

$5^{a}$ parada - Castelo da Barra. Ao longo do percurso no bairro, os (as) estudantes perceberam que nos muros de algumas residências havia pinturas 
e murais que retratam o cotidiano do bairro em si, como o congo, a pesca, surf, etc. Expressões artísticas que ressaltam o caráter cultural e ambiental do bairro. E por fim, a atração turística do castelo.

$6^{a}$ parada - Caminhada ecológica no Morro da Concha. Nesse local, os (as) estudantes avistaram a verticalização do litoral de Vila Velha, parte do curso do Rio Jucu e o encontro do rio com o mar (foz ou exutório). Puderam identificar as principais formas de relevo; observar toda a extensão do cordão arenoso que dificulta a passagem do Rio Jucu, constituindo-se como uma barreira natural que modifica o curso do rio, além da presença e importância da vegetação de restinga no Parque Natural Municipal de Jacarenema.

\section{Não importa a cor, não importa teu jeito (Noite, 2002)}

O pós-campo teve como objetivo a produção de histórias em quadrinhos, a partir das experiências vivenciadas durante todo o processo. Cada turma foi dividida em 5 grupos com temas diferentes. São eles: manguezal, restinga, poluição dos corpos hídricos, relevo, mata ciliar. Ao final, tivemos a produção de 15 histórias em quadrinhos com diferentes narrativas.

Figura 3 - Produção das HQs

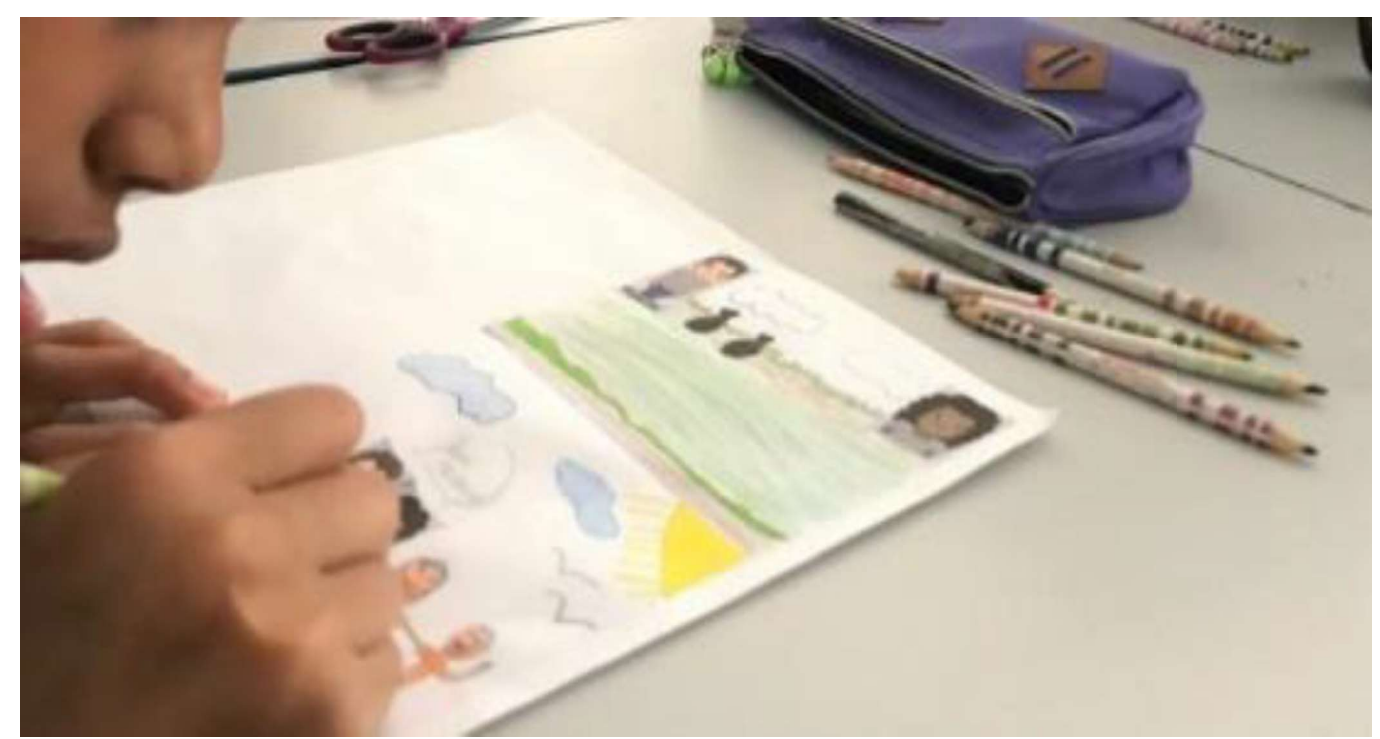

Fonte: Autoria própria (2019)

Ao tencionar as (os) estudantes com uma proposta não usual, obtivemos certa resistência dos mesmos, que se mostraram desanimados e desinteressados, o que comprometeu inicialmente o desenvolvimento da 
atividade. Entretanto, quando entenderam de fato o objetivo do trabalho e viram que teriam liberdade para se expressar, esse desinteresse foi se transformando em entusiasmo, com isso, o desenvolvimento e a agilidade na produção foram notáveis.

Como resultado, observamos as diversas percepções acerca dos conteúdos trabalhados por meio das interpretações e leituras das histórias em quadrinho. Ficou evidente a postura crítico-reflexivo, que propomos construir/fortalecer ao longo do processo. Em uma das HQs foi perceptível a associação dos cílios dos olhos com a mata ciliar e o uso da fala de um jornal local, o que nos confirma a aproximação dos saberes teóricos ao cotidiano dos(as) estudantes. Para fins demonstrativos, escolhemos entre as quinze narrativas produzidas, uma história para ilustrar os resultados obtidos.

Figura $4-\mathrm{HQ}$ produzida pelos alunos sobre Mata Ciliar

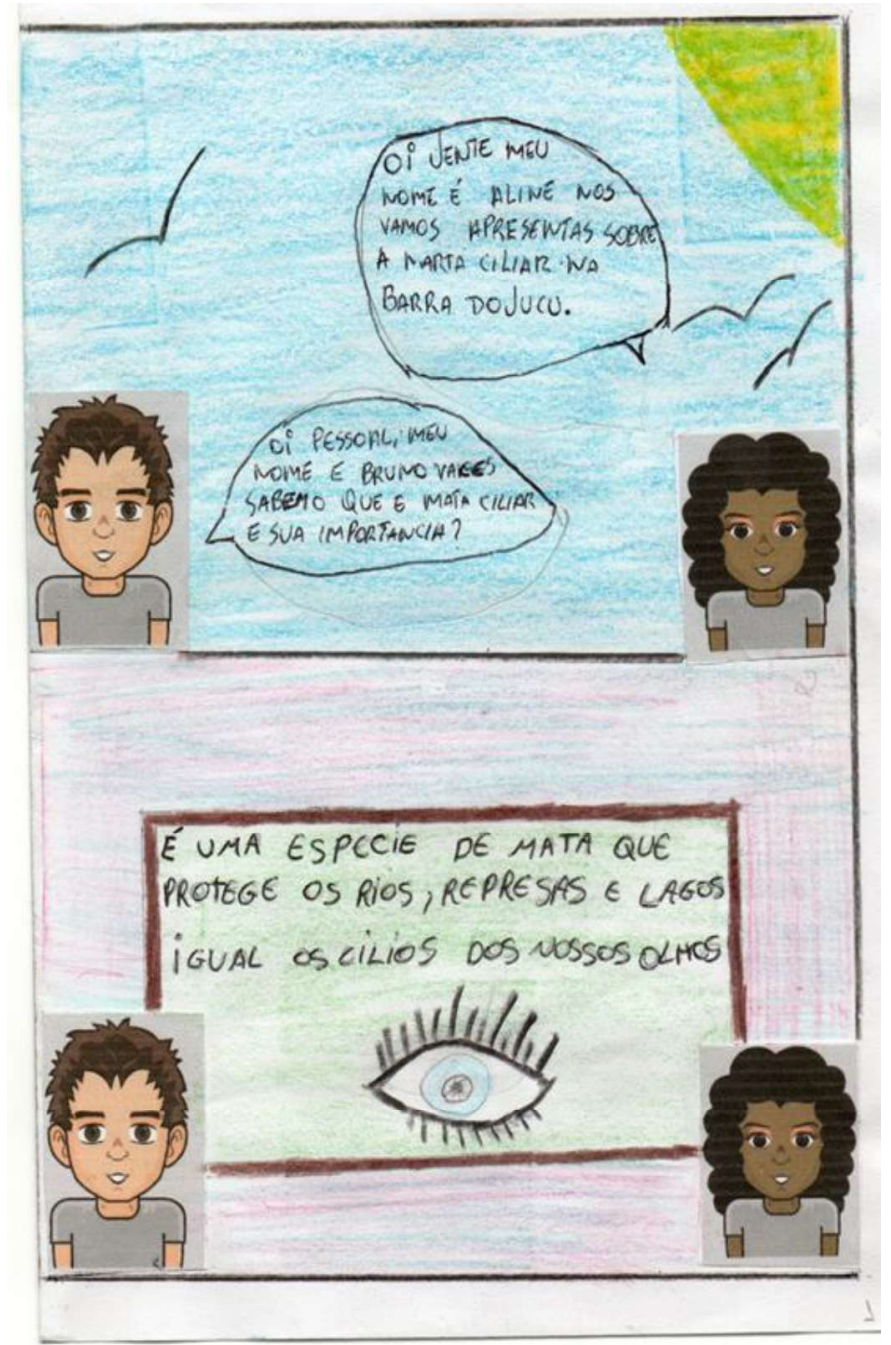



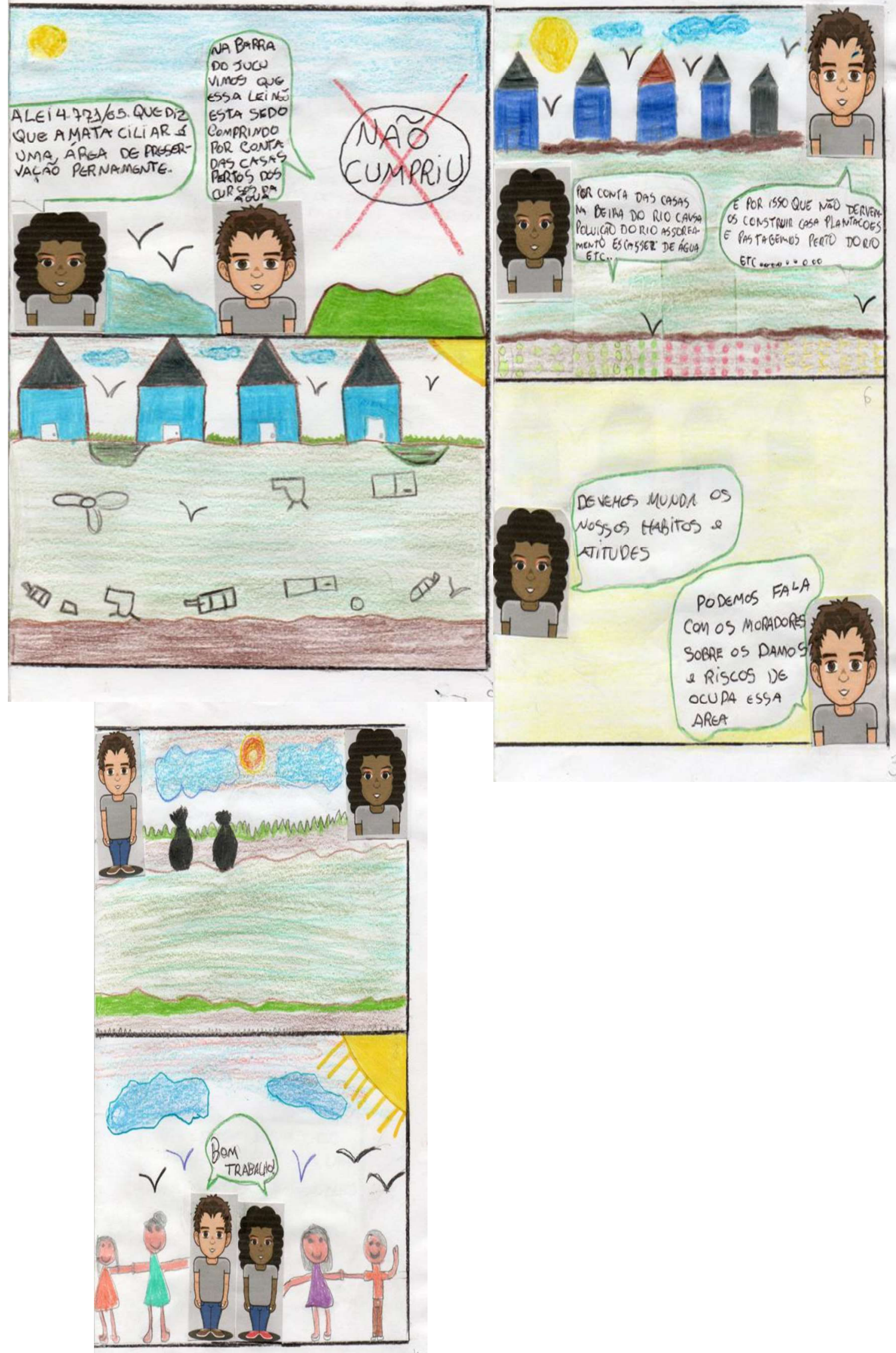

Fonte: Produção dos alunos (2019) 


\section{Um momento de paz, loucura e aventura (Ondas, 2001)}

A aula de campo preenche a parte empírica do processo de ensinoaprendizagem e molda a relação do (a) estudante com os recursos inerentes ao seu cotidiano. O pós-campo amparou-se na produção de histórias em quadrinhos a partir das percepções e conhecimentos adquiridos ou ressignificados. Percebe-se que os(as) estudantes têm uma visão diferente dos temas que foram trabalhados. A todo momento, é possível identificar a afinidade dos (as) estudantes com o que foi visto na aula de campo e a representatividade colocada no papel quando se deu início à produção das histórias em quadrinhos.

As HQs produzidas pelos (as) estudantes foram instrumentos importantes para valorizar a criatividade e a autonomia nos mais diferentes modos de aprendizagem. Viabilizando a interdisciplinaridade com Artes, na produção de desenhos; Ciências, relacionando e agregando com temas também presentes na Geografia; Língua Portuguesa, importante na elaboração dos textos para a montagem das histórias, entre outras áreas. A interdisciplinaridade é essencial dentro e fora de sala de aula para que os(as) estudantes não tenham visões limitadas e fragmentadas sobre o que está acontecendo ao seu redor. Na utilização da atividade lúdica - no caso, a criação de histórias em quadrinhos com conteúdo elucidados na aula de campo - foi notório o entusiasmo dos (as) estudantes em relação ao conteúdo que estava sendo abordado, por oportunizar sua livre expressão, ação e interação em sala de aula.

Ao inovar em metodologias e abandonar os métodos e técnicas tradicionais, descobriu-se que o lúdico é eficaz e eficiente como estratégia didática. Constatou-se que os (as) estudantes se aproximaram do conteúdo por haver uma maior participação e envolvimento durante todo o percurso de ensino. A observação da paisagem em um local onde há possibilidade de abordar diversos temas a serem trabalhados dentro da Geografia fez com que o pensamento dos(as) estudantes se ampliasse, o que não seria tão eficaz se estes estudassem apenas através do modo tradicional de ensino. Paralelamente, foi determinante à execução de uma tarefa em que lembranças, 
análises e criatividade dos(as) estudantes viessem à tona para que os conteúdos abordados em sala de aula e em campo pudessem ter eficácia no que diz respeito à produção de materiais de qualidade. A metodologia da aula de campo, ainda que demande um maior investimento de tempo e recursos, cria benefícios para deixar o ambiente escolar mais maleável e suscetível a novas abordagens e metodologias. A partir do ponto de vista teórico, entendese a aula de campo como instrumento de análise do espaço geográfico de forma incisiva, relacionando-a a assuntos previamente abordados em sala de aula. Desse modo, os (as) estudantes têm a oportunidade de vivenciar sensações de identificação com o cotidiano em que estão inseridos (as), além de experienciar interesses desenvolvidos pela cultura humana, a busca pela compreensão do lugar e os recursos inerentes à sua sobrevivência.

Por outro lado, mas não distante, a parte prática da aula de campo é instrumento agradável ao estudante dentro da realidade escolar. O ensino tradicional limita a expansão de conhecimentos que um (a) estudante pode obter ao analisar qualquer tipo de ciência. Estar em contato direto com a teoria e prática possibilita alcançar diversas potencialidades de ensino que a Geografia oferece. A aula de campo promove uma ação que, dentro da metodologia tradicional, é pouco utilizada e a possibilidade de o (a) estudante expandir seus saberes para além da sala de aula deve ser valorizado pelo docente. Por fim, ressaltando o inegável alcance dos objetivos propostos, os estudantes conseguiram de forma positiva fazer a aproximação do conteúdo desenvolvido em sala de aula com aquilo que foi visto no campo. Isso confirma a ideia de que a aula de campo é um recurso útil para uma aprendizagem significativa.

\section{Agradecimentos}

Agradecemos a todos aqueles que contribuíram de alguma forma para que esse trabalho fosse concluído. O presente trabalho foi realizado com apoio da Coordenação de Aperfeiçoamento de Pessoal de Nível Superior - Brasil (CAPES) - Código de Financiamento 001. 


\section{Referências}

ALVES, Nilda. Decifrando o pergaminho: o cotidiano das escolas nas lógicas das redes cotidianas. In: OLIVEIRA, Inês Barbosa de; ALVES, Nilda (Org.). Pesquisa no/do cotidiano das escolas: sobre redes de saberes. Rio de Janeiro: DP\&A, 2001.

BATUQUEIRO. Intérprete: Banca Casaca. In: CASACA. Intérprete: Banda Casaca, Sony Music, 2002.

BRASIL. Lei $\mathbf{n}^{\circ}$ 9.394, de 20 de dezembro de 1996. Estabelece as diretrizes e bases da educação nacional. Brasília, DF: Congresso Nacional, 1996. Disponível em: http://www.planalto.gov.br/ccivil 03/leis/l9394.htm Acesso em: 02 set. 2020.

BRASIL. Base Nacional Comum Curricular. Brasília: MEC, 2017. Disponível em: http://basenacionalcomum.mec.gov.br/ Acesso em: 02 set. 2020.

FERRAÇO, Ricardo. Pesquisa com o cotidiano. Educação \& Sociedade, São Paulo, v. 28, n. 98, 2007.

FREIRE, P. Pedagogia do oprimido. 17.ed. São Paulo: Editora Paz e T erra, 1987.

FREIRE, P. Pedagogia da autonomia - saberes necessários à prática educativa. 25.ed. São Paulo: Editora Paz e Terra, 2001.

HENRIQUE, Junior. et al. "Potencialidades da aula de campo no estudo de Geografia na região da foz do rio Jucu no bairro Barra do Jucu, Vila Velha/ES. 2019. Trabalho de Conclusão de Curso - Universidade Federal do Espírito Santo, Vitória, 2019.

NOITE fria. Intérprete: Banca Casaca. In: CASACA. Intérprete: Banda Casaca, Sony Music, 2002.

ONDAS do Barrão. Intérprete: Banca Casaca. In: NA CASACA no tambor na guitarra. Intérprete: Banda Casaca, Sony Music, 2001.

SEU novo mundo. Intérprete: Banca Casaca. In: CASACA EP. Intérprete: Banda Casaca, lançamento independente, 2007.

TEMPO. Intérprete: Banda Casaca. In: TEMPO. Intérprete: Casaca, lançamento independente, 2010.

\section{Sobre os autores}

\section{Rômulo Marconi Carneiro}

romulomarconi@icloud.com

Licenciando em Geografia - UFES. Técnico em Geoprocessamento - IFES. 
Karolayne Pinheiro dos Santos

Karolayne_pinheiro@hotmail.com

Graduada em Geografia - UFES.

\section{Tainá Guimarães Ricardo}

taina.guimaraess@gmail.com

Graduada em Geografia - UFES. Pós-Graduada em Gestão do Trabalho Pedagógico - UNINTER, Especialista em Educação, Pobreza e Desigualdade Social - UFES. Professora de Geografia da rede pública municipal de Vila Velha/ES. 